\title{
Hot-melt extrusion technique: A novel continuous manufacturing method for enteric-coated pellets
}

\author{
Rajeshwari Roychowdhury ${ }^{1 \dagger}$, Divya Dhatri $\operatorname{Kara}^{2 \dagger}$, Mahalaxmi Rathnanand ${ }^{2 *}$ \\ ${ }^{1}$ Manipal College of Pharmaceutical Sciences, MAHE, Manipal, India.. \\ ${ }^{2}$ Department of Pharmaceutics, Manipal College of Pharmaceutical Sciences, MAHE, Manipal, India.
}

\begin{tabular}{l}
\hline ARTICLE INFO \\
\hline Received on: $11 / 12 / 2020$ \\
Accepted on: $13 / 04 / 2021$ \\
Available online: $05 / 07 / 2021$
\end{tabular}

\section{Key words:}

Hot-melt extrusion (HME), enteric-coated pellets, pelletization, twin screw extruder, novel drug delivery system (NDDS).

\begin{abstract}
The technology of hot-melt extrusion (HME) is becoming a progressively appealing way to develop different drug delivery systems. A wide range of pharmaceutical dosage forms and formulations from oral to topical and parenteral can be prepared. The dosage forms formulated using HME technique are composite mixtures of active pharmaceutical agents, active excipients, and other processing aids. HME has many advantages over traditional techniques of pharmaceutical development, such as non-solvent technology, lower processing requirements, uninterrupted activity, and greater possibility of uniform suspension and increased bioavailability. This paper addresses enteric-coated pellet pharmaceutical applications and its process techniques using the HME technology and its applications in pharmaceutical industries for an efficient pathway for a novel drug delivery system.
\end{abstract}

\section{INTRODUCTION}

Over the past years, many kinds of dosage forms have been discovered, but the problem of solubility is still a major issue. To overcome this, pellets were devised by various techniques. Pellets in the pharmaceutical industry are small, free-flowing, spherical, or semi-spherical units that are produced using suitable processing equipment to agglomerate fine powders of bulk medication and excipients (Ghebre-Sellassie and Knoch, 2002).

The appearance, flow, and physicochemical characteristics of fine powders can be improved by pellet formulation (Vyas and Jain, 2019). Pellets can be used to develop controlled and targeted drug delivery systems, such as entericcoated pellets, which prevent the degradation of acid-sensitive drugs in the stomach and provide targeted drug delivery to the intestine.

\section{*Corresponding Author}

Mahalaxmi Rathnanand, Department of Pharmaceutics,

Manipal College of Pharmaceutical Sciences, MAHE, Manipal, India.

E-mail:mahalaxmi.r@manipal.edu

†Both the authors contributed equally.
Enteric coating of pellets can be carried out by techniques such as extrusion and spheronization (Raval et al., 2013), fluidized bed coater, powder layering, and so on.

One of the techniques that has emerged as a promising method for developing enteric-coated pellets and other dosage forms is hot-melt extrusion (HME). It is an unremitting procedure which involves the use of heat and pressure to melt the active drug and polymers to give an amorphous mixture. The materials are melted above their glass transition temperatures with the help of a screw(s) which rotates at a predetermined rpm. The product obtained at the end of the process has many benefits over the ones prepared by conventional means such as enhanced solubility, bioavailability, absence of $\mathrm{pH}$-dependent degradation of the product, taste-masking of water-soluble drugs, etc. (Patil et al., 2016).

\section{Process of pelletization}

Pelletization is a form of the process through agglomeration that transforms granules of bulk drug powders into pellets (Kandukuri et al., 2009). It is frequently denoted as a size-amplification procedure in which agglomerates of narrow size (0.5-2.0 mm mean size) called pellets are formed (Deb and Ahmed, 2013). 
The major steps involved in the mechanism of agglomerate formation and the subsequent formation of pellets are nucleation, coalescence, layering, ball growth, and abrasion transfer (Fig. 1).

Nucleation or nuclei development denotes to the growth of primary particles from a continuous phase due to interactions within the environment itself (Yadav and Verma, 2016). Smaller the size of the particles, greater the bond strength (Capes, 2013).

The nucleation phase is succeeded by the transition phase which involves coalescence and layering stages. After the formation of nuclei, coalescence begins, which leads to a change in size and agglomerates keep their mass intact (Juslin, 1997; Kristensen and Schaefer, 1987).

Coalescence is followed by layering in which small particles and fines are deposited successively on the previously formed nuclei. This phase corresponds to a slow growth phase. The particles continuously change their size upon interaction with the continuous phase and the process can only happen when agglomerates and fresh feed are equally present. All these changes occur concurrently during all the pelletization processes, unless the process parameters have been differently chosen (Manivannan et al., 2010).

During the growth phase of the ball, abrasion transfer occurs, which causes the transfer of particles from one formed granule to another, happening in either direction, thus affecting the slow growth of agglomerates (Hinder and Kelly, 1977; Yadav and Verma, 2016).

The processing of pellets entails the fulfillment of certain criteria, such that they must be as close to a spherical with a smooth surface for optimal film coating and improved flow characteristics. It is most preferable if they have a narrow particle size range. The ideal size of pellets is between 600 and $1,000 \mathrm{~mm}$ for pharmaceutical use. The pellets should contain a sufficient amount of active ingredients to preserve a fair amount of the size for the final dosage form (Ankit et al., 2013). They should have the optimum mechanical strength to withstand abrasion during transportation, handling, storage, and other processes (Yadav and Verma, 2016).

Advantages of pellets in the pharmaceutical field (Ghai, 2011; Hirjau et al., 2011; Kumari et al., 2013; Rahman et al., 2009) are uniformity of dose, flexibility in dosage form and design, appropriate for controlled release technology, reduced

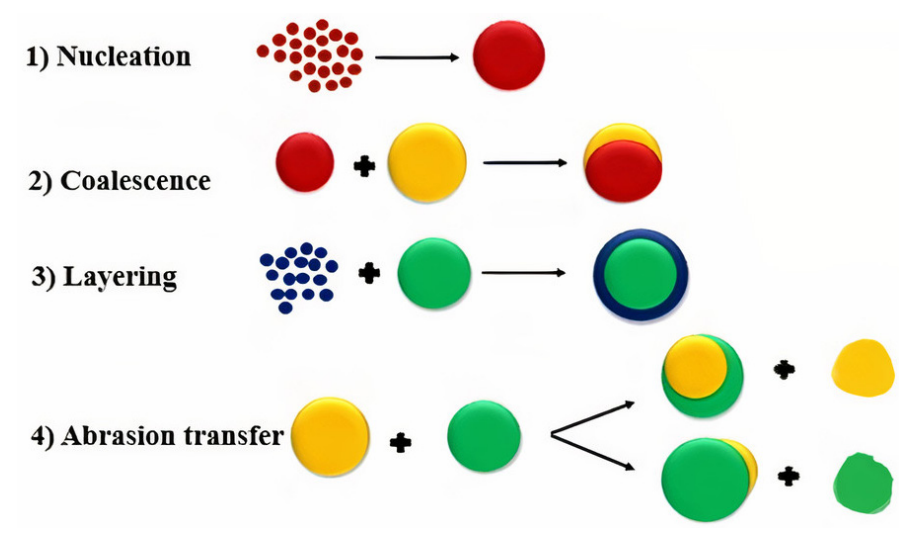

Figure 1. Mechanism of agglomerate formation. peak plasma fluctuations, increased absorption by dispersing freely in the gastrointestinal tract (GIT), prevents high local concentration of the drug because of wide distribution, and nondusting in nature; both chemically compatible and incompatible active pharmaceutical ingredients (APIs) can be formulated into a single type of dosage form and can be delivered to the same or different sites of the GIT, applicable for taste-masking of bitter drugs and reducing gastric-emptying, thereby minimizing the inter- and intra-patient variability, thereby overcoming the problems encountered by conventional tablets.

\section{Enteric-coated pellets}

Enteric coating is carried out when pellets loaded with drugs are degraded at lower $\mathrm{pH}$ levels of the stomach. Entericcoated pellets are the pellets which are coated with a polymer barrier that helps them to remain intact in the stomach and prevent the degradation of the drug in the gastric environment (Hirjau et al., 2011). They also prevent the pellets from producing gastric irritation.

Reasons for enteric coating include protection of drugs which are acid-labile from the gastric environment, thus preventing nausea and gastric distress, providing localized action of the drug in the intestine, and providing a delayed release of the drug (Swathi, 2017).

The drawbacks of enteric coating formulation are as follows: while formulating the enteric-coated dosage forms, mechanical properties of the applied coating material should be taken into consideration. During storage and handling, cracking of the film may occur which may result in loss of enteric properties of the drug. A plasticizer, preferably of a non-water-soluble material, can be used, which protects the film from cracking as well as reduces the water vapor permeability of the polymer material. Generally, the rule of 1 part plasticizer and 10 parts polymers is used (Lachman et al., 1986).

The materials used for enteric coating are macromolecules like polymers which have a molecular weight in the range 10,000 to several million Dalton. They are capable of providing delayed release of the drug and enteric resistance, thus protecting the drug from the acid environment of the GIT. Common materials used for enteric coating are shellac, acrylic resins, methacrylic acid copolymers, polymethacrylic acid/acrylic acid copolymer, hydroxypropyl methylcellulose phthalate, hydroxyethyl ethylcellulose phthalate, polyvinyl acetate phthalate, cellulose acetate, and cellulose acetate tetrahydro phthalate. Methacrylic acid copolymers are the most commonly used group of polymers for enteric coating. They are insoluble in acids (dilute), gastric fluids, and pure water and can dissolve by salt formation at a $\mathrm{pH}$ between 5 and 6. They are available as Eudragit ${ }^{\circledR}$ L and S (Chen, 2004; Chien, 1989; Rowe et al., 2009; Vyas and Khar 2002).

\section{Different pelletization techniques}

There are several techniques (Fig. 2) receiving attention for preparation of these pellets and the most commonly used techniques are listed in Figure 2.

From these techniques, due to its efficiency and scalability, HME has now been used more widely in pharmaceutical industries for production of variety of dosage forms including pellets because of its numerous advantages like improving the 
Layering Technique (Powder Layering \& Suspension Layering)

Extrusion \& Spheronization

Hot Melt Extrusion

Cryopelletization

Freeze Pelletization

Spherical Agglomeration (Liquid-induced \& Melt-induced)

Spray Drying \& Spray Congealing

Figure 2. Different pelletization techniques.

Table 1. Application of HME in the development of pellets.

\begin{tabular}{ll}
\hline Formulation & Drugs used \\
\hline Delayed release (Enteric coated) pellets & Ketoprofen and Ibuprofen \\
Sustained release pellets & Diltiazem hydrochloride \\
Sustained release pellets & Chlorpheniramine maleate \\
Controlled release pellets & Theophylline \\
Controlled release pellets & Diclofenac sodium \\
Targeted drug delivery & Ketoconazole \\
Mini matrices pellets & Metoprolol tartarate \\
\hline
\end{tabular}

solubility and bioavailability of poorly water-soluble drugs (Vynckier et al., 2015).

\section{HME technique}

HME is the utmost valued and efficient technique used in food, plastics, and rubber industry. It is used in the manufacturing of many plastic products like bags, sheets, tubes, pipes, foams, etc. $\mathrm{HME}$ is an innovative and efficient technology for manufacturing different dosage forms and drug delivery systems in the pharmaceutical industry (Madan and Madan, 2012). HME is a green synthesis technique as it avoids the use of organic solvents showing maximum scalability using the process. Researchers have been working on pellet formulations of different drugs using HME as shown in Table 1 (Ahir et al., 2015; Politis and Rekkas, 2011).

\section{Applications of HME}

HME is a novel and robust technology in the pharmaceutical industry used for manufacturing various drug delivery systems like sustained-release (SR) and delayed-release (DR) drug delivery systems. It is also used for processes like tastemasking, bioavailability enhancement, and production of films for transmucosal and transdermal drug delivery systems and also for developing amorphous materials (Madan and Madan, 2012).

\section{Extrusion process}

Extrusion process is of two types: ram extrusion and screw extrusion. Screw extrusion involves extrusion with the help of a gyrating screw in a heated barrel, whereas in ram extrusion, instead of a screw, a ram or plunger is used. This ram or plunger causes a positive displacement which produces a high pressure and helps to push the materials through the die (Crowley et al.,
2007). HME comes under the screw extrusion process. In screw extrusion, the drug and the pharmaceutical excipients are melted by a screw at a specific temperature and then the homogenized mass is extruded through a die. This process provides a continuous output of products (Ghebre-Sellassie and Knoch, 2002) and it also provides more amount of sheer stress and mixing.

A screw extruder consists of four separate parts: the opening for the material to enter the barrel, a conveying system which transports and mixes materials, a die or orifice for the shaping of the extrudate, and downstream auxiliary equipment for collecting the finished products (Griff, 1976; Wilson et al., 2012). Other distinct parts of the screw extruder include a hopper for feeding of materials, a barrel with controlled temperature, rotating screw, die, and a system to maintain the temperature for heating or cooling purposes (Maniruzzaman et al., 2012). extruder.

HME is available in two types, a single and a twin-screw

Single Screw Extruder: In a single screw extruder, a single screw rotates inside a barrel and one screw is responsible for feeding, melting, devolatilizing, and pumping (Crowley et al., 2007). Depending on the production process requirements, the single screw extruder can be fed or starve-fed (Luker, 2012). After the material is fed through the hopper, the material is conveyed along the screw enclosed in the barrel. After the material is conveyed, the heated barrel produces a melt. The formation of the melt is contributed to the energy from the heaters and the intense shearing capacity of screw extrusion.

Twin Screw Extruder: As the name indicates, twinscrew extruder involves the working of two screws. These screws can rotate in the same or opposite direction. If they rotate in the same direction, it is called co-rotating extruder and if it rotates in the opposite direction, it is called counter-rotating extruder (Crowley et al., 2007). Furthermore, they can be distributed into non-intermeshing and complete intermeshing out of which complete intermeshing is the most popular type of twin-screw extruder (Martin, 2013). Fully intermeshing type of twin-screw extruder prevents the overheating of the extrudate. This kind does not allow the material to rotate along the screw. Non-intermeshing type of twin-screw extruders is used for producing highly viscous materials. In this, the screws are positioned apart from each other and thus the non-intermeshing extruders permit large volume devolatilization through an outlet (Crowley et al., 2007).

Irrespective of the kind of screw inside the barrel, extrusion equipment consists of a motor, a barrel, rotating screw, and a die (Chokshi and Zia, 2004). An electronic control unit is also connected along with the extrusion equipment to control the various process parameters, such as temperature, pressure, screw speed, and to monitor the process (Maniruzzaman et al., 2012)

In the extrusion process, the screw design is very important since it defines the product type that is produced. The design or dimensions of the screw is determined by lengthdiameter ratios (L/D) (Griff, 1976). The L/D ratio of the screws inside the barrel decides whether the single or twin-screw extruder is to be used. The L/D ratios vary in the two cases between 20 and 40:1 (mm) (Andrews et al., 2008; Maniruzzaman et al., 2012).

A base screw in the single-screw extruder has a threepiece feeding zone, a melting area, and a metering area. The feeding zone is responsible for transferring the material to the 
barrel from the hopper. The compression zone softens or melts the material. The metering zone provides uniform product delivery from the die. The die controls the shape of the extrudate at the end of the barrel (Crowley et al., 2007; Maniruzzaman et al., 2012).

A single screw is quick and economical, although it does not have the same mixing power as a twin-screw extruder. A twin-screw extruder is more prevalent as it provides greater optimization and process manipulation; hence, it is used more in the pharmaceutical companies than the others. Twin-screw extruders provide easier feeding of material, prevention of overheating, and shorter residence time which are attainable using an intermeshing type of twin-screw extruder (Repka et al., 2007)

\section{Process technology of twin-screw extruder process}

Twin-screw extruder method involves the transfer of a blend of the raw materials like polymer and powdered excipients with a rotating screw inside the extruder through the hot barrel (Lindén, 2012). The die at the end of the extruder continuously pumps the molten mass which is then solidified rapidly when it is exiting the equipment (Keen and McGinity, 2013).

The three different parts of the screw, i.e., the feeding, melting, and metering sections play an important part in the formation of the extrudate. They are set at specific pre-defined temperatures before the initiation of the process (Fig. 3 and Crowley et al., 2007).

The feeding section facilitates the transport of the material from the hopper to the barrel and ensures mass flow, softening, and melting of the polymer (Lindén, 2012). Mass flow is an important requirement and to achieve it, it should be made sure that the feed material has good flow properties and care should be taken that the hopper angle exceeds the materials' angle of repose. If the materials used do not have good flow properties, it would lead to a non-uniform flow which would then require a force-feeding device to ensure proper transfer by the rotating screw (Crowley et al., 2007; Doetsch, 2003).

As the feed moves across the barrel, thermal energy is produced by shearing of the rotating screw and from the electrical heating bands by conduction. Feeding efficiency depends on various factors like bulk density, flow and compression properties, and the particle shape of the raw materials used a swell as the coefficient of friction between the surface of the screw and barrel and the raw materials. Resistance inside the barrel provides the required driving motion to the material and the friction on the surface of the screw prevents the feed material from going forward (Luker, 2012).

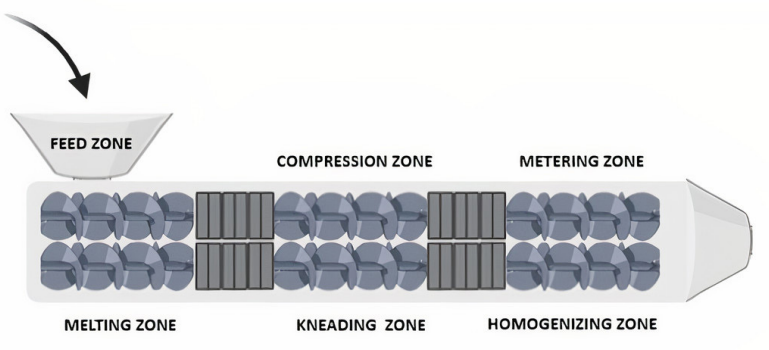

Figure 3. Illustration of a twin-screw HME.
The melting region is usually held at a temperature between 15 and $60^{\circ} \mathrm{C}$, i.e., over the melting point of polymers that are semi-crystalline or at the amorphous polymers' transitional temperature.

Polymer properties and the design of the extruder are crucial in maintaining the efficiency of the melting procedure. Some changes in screw design can also contribute to the process of melting. The metering zone helps in maintaining transfer of the material from the die. The die cavity is important in determining the form of the extrudate (Rauwendaal, 2014). Later the extrudate is converted into spherical or rod-shaped strands (Fig. 4).

\section{Processing parameters of HME}

The processing parameters are crucial in determining the properties of the extrudates. Parameters like screw speed, temperature, and feed rate affect the shear stress as well as the mean residence time, stability, and dissolution rate of the final product. As the processing parameters mainly depend upon the polymer used, its physical and chemical properties should be determined and maintained to get proper results (Lindén, 2012).

\section{Mechanism of HME}

In HME, the bulk materials are fed through the barrel either by starve-feeding (the materials fed are conveyed to the screws directly and the feed rate and output of product are independent of the screw rpm) or flood-feeding (the screw rpm determines the product formation). Starve-feeding is preferred as it prevents the chances of accumulation of feed materials near the hopper, decreases the torque, and provides uniformity and efficiency in heat transfer. After the materials are fed, they undergo softening or melting due to a high temperature and shear provided by the instrument. The physical mixture then undergoes further melting, resulting in a molten mass. Melting of the mass depends on a few conditions such as physical attributes of the materials fed, feed type, processing temperature, torque, rpm, and so on. The final step of the process involves the cooling and shaping of the extrudate, which also depend on the physical and thermal properties of the extruded mass, processing conditions such as temperature, torque, rpm, and the shape and design of the die and other auxiliary equipment which determine the shape of the equipment (Thakkar et al., 2020).

\section{HME for enteric-coated pellets}

Depending on the polymer employed and its properties, the pellets prepared via HME has the unique advantage of having

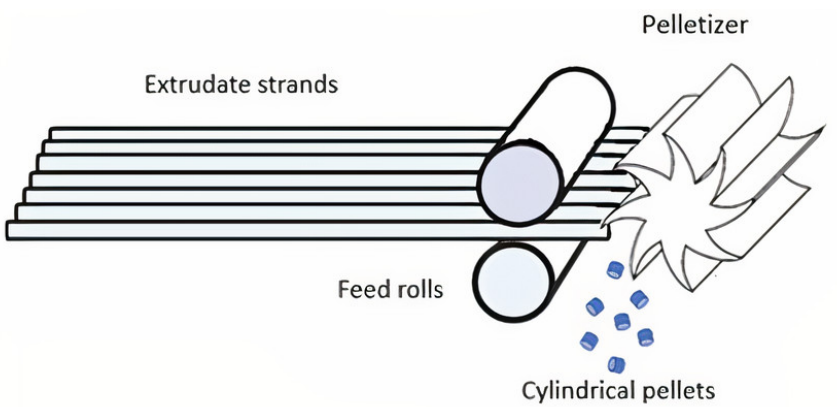

Figure 4. A diagrammatic illustration of a pelletizer. 
immediate-release or controlled-release properties. HME pellets do not require an additional film coating to alter the drug release properties unlike the pellets prepared by conventional methods which need to be coated to prevent rapid drug release. HME pellets can be further enteric-coated to suit their requirements (Young et al., 2003).

Thus, HME reduces the need for an additional coating, thus reducing any potential side effects from polymers used for the coating process. It also eliminates an extra step in the manufacturing process, thereby saving time and cost. One of the other advantages of using HME for preparing enteric-coated pellets is the incorporation of high temperatures. Often, the polymers with high glass transition temperatures pose certain problems, while coating pellets using conventional methods and this difficulty can be overcome by using HME technology (Yang et al., 2017).

\section{Disadvantages of HME in the formulation of enteric-coated pellets}

The main disadvantage of using HME in the formulation of enteric-coated pellets is use of high temperatures during processing. Thermo-labile drugs or polymers cannot be handled under such conditions as they undergo degradation (Maniruzzaman et al., 2012).

\section{Formulation of enteric-coated pellets using HME technique in the recent times}

Jankovic et al. (2019) studied the performance of amorphous solid dispersions of Ketoconazole by preparing them utilizing HME. Initially, extrudates were formed which were further pelletized using a twin-screw extruder. The pellets were entericcoated using hydroxy propyl methylcellulose acetate succinate (HPMCAS). Drug release of ketoconazole from the amorphous solid dispersions was studied using different grades of HPMCAS. From this study, it was concluded that the crystallization of weakly basic drugs can be prevented using amorphous solid dispersions.

Vo et al. (2020) applied quality by the design approach in the continuous manufacturing of delayed release pellets of ketoprofen using a twin-screw co-rotating extruder. Eudragit was used as a polymer for enteric-coating. HME was proved to be a useful technique for continuous manufacturing of DR pellets.

Schilling et al. (2010) researched on the enteric matrix pellets that were prepared by HME in a continuous uni-step process were examined and concluded that they were more effective when used in conjunction with the extrusion system with better entericcoated polymers.

Schilling et al. (2010) examined the possible benefits of HME compared to direct compression for the production of Eudragit ${ }^{\circledR}$ L-coated polymer soft-drug granules for a newer application in the preparation of multi-particulate matrices of retarded-release particles (Schilling and McGinity, 2010).

Follonier et al. (1995) investigated different methods for modifying the release of diltiazem hydrochloride from extruded, hot-melt pellets made of polymer-based materials which were examined. They also found that the HME provides a continuous process of multiple units' continuous release dosage types. They also included that because of the low vacuum fraction of such systems, the quantity of polymer necessary for the continuous release of the drug was reduced too. They noted that the high dose, freely soluble drugs such as diltiazem hydrochloride are very suited for producing SR pellets.

Dumpa et al. (2018) developed a chronotherapeutic delivery of drugs like Ketoprofen and Ibuprofen for an enhanced therapy for early morning stiffness in arthritis using the HME technology and concluded that HME is a novel, viable technique suitable for developing a chronotherapeutic drug delivery system with many advantages compared to those of other traditional techniques.

Young et al. (2003) investigated the properties of drug-containing spherical pellets produced by a HME and spheronization process and clinched that spherical pellets can be manufactured using the HME and spheronization process. They added that spheronization and HME are a continual activities and do not involve a long drying process due to the lack of water or other solvents during the production process. They finally clinched that melt-extruded pellets displayed a narrower distribution of particle size compared to pellets prepared by traditional wet-mass extrusion.

Young et al. (2007) investigated the physicochemical properties of film-coated melt-extruded pellets and concluded that HME supplies melt-extruded beads with $\mathrm{pH}$-dependent drug release properties which were robust when stored under accelerated conditions.

\section{Advantages of HME in the formulation of enteric-coated pellets}

From the above-listed works, it can be deduced that HME has several advantages over the traditional methods for the preparation of enteric-coated pellets. No solvent is required in the process, thus reducing the risk of chemical degradation of the drug by water. It is also considered as a green technology. It provides modified drug release (delayed, sustained), thus making it possible to mix drugs with polymers with specific solubility. Entericcoated pellets by HME shows improved bioavailability of drugs. Improved drug homogeneity is caused by the uniform dispersion of the drug in the molten mass. HME is a continuous process. Scaleup is easy as the HME process can be easily followed by process analytical techniques devoid of conventional processing problems like flowability and the compressibility of API. It provides good stability of the final product at varying $\mathrm{pH}$ and moisture conditions. Few processing steps, less time-consuming, less wastage, and so on provide more yield with least contamination and cost-effective process (Censi et al., 2018; Ghebremeskel et al., 2007; Hengsawas Surasarang et al., 2017; Hitzer et al., 2017; Jaiswar et al., 2016; Maniruzzaman et al., 2013; Martin, 2008; Organization, 2009; Thiry et al., 2015).

\section{CONCLUSION}

HME is a booming technology used in diverse industries like the plastics industry and the food industry. In the pharmaceutical arena, it is a relatively novel technique which offers many advantages over the traditional methods used for developing enteric-coated pellets. Bioavailability, as well as solubility enhancement, no requirement of solvents, taste-masking, and improved properties like dissolution rate in DR dosage forms are some of its sundry advantages. Like any other technique, HME also has certain disadvantages like the requirement of high 
processing temperature, difficulty in scale-up, and lack of enough process knowledge. However, these limitations can be overcome by applying different engineering concepts or modifying the experimental layout. With its vast scope and potential and a plethora of benefits, HME can be exploited further in the development and preparation of enteric-coated pellets and other novel drug delivery systems.

\section{ACKNOWLEDGMENTS}

The authors would like to thank the Manipal College of Pharmaceutical Sciences, MAHE, Manipal, India. The authors are also thankful for Biorender.com, an image-making tool.

\section{AUTHOR CONTRIBUTIONS}

All authors made substantial contributions to conception and design, acquisition of data, or analysis and interpretation of data; took part in drafting the article or revising it critically for important intellectual content; agreed to submit to the current journal; gave final approval of the version to be published; and agree to be accountable for all aspects of the work. All the authors are eligible to be an author as per the international committee of medical journal editors (ICMJE) requirements/guidelines.

\section{FUNDING}

There is no funding to report.

\section{CONFLICTS OF INTEREST}

The authors report no financial or any other conflicts of interest in this work.

\section{ETHICAL APPROVALS}

Not applicable.

\section{PUBLISHER'S NOTE}

This journal remains neutral with regard to jurisdictional claims in published institutional affiliation.

\section{REFERENCES}

Ahir AA, Mali SS, Hajare AA, Bhagwat DA, Patrekar PV. Pelletization technology: methods and applications-a review. Res J Pharm Technol, 2015; 8(2):131-8.

Andrews GP, Margetson DN, Jones DS, McAllister SM, Diak OA. A basic guide: hot-melt extrusion. UKICRS, Rochester, United Kingdom, vol. 13, 2008

Ankit B, Rathore RPS, Tanwar YS, Gupta S, Bhaduka G. Oral sustained release dosage form: an opportunity to prolong the release of drug. IJARPB, 2013; 3(1):7-14.

Capes CE. Particle size enlargement. Elsevier, Amsterdam, Netherlands, vol. 1, 2013.

Censi R, Gigliobianco MR, Casadidio C, Di Martino P. Hot melt extrusion: highlighting physicochemical factors to be investigated while designing and optimizing a hot melt extrusion process. Pharmaceutics, 2018; 10(3):89.

Chen JR. Preparation of enteric pharmaceutical dosage forms for omerprazole and lansoprazole [Internet]. 2004. Available from: https:// patents.google.com/patent/US6726927B2/en (Accessed 10 Nov 2020).

Chien YW. Rate-control drug delivery systems: controlled release vs. sustained release. Med Prog Technol, 1989; 15(1-2):21-46.

Chokshi R, Zia H. Hot-melt extrusion technique: a review. Iran J Pharm Res, 2004; 3:3-16.
Crowley MM, Zhang F, Repka MA, Thumma S, Upadhye SB, Battu SK, McGinity JW, Martin C. Pharmaceutical applications of hot-melt extrusion: part I. Drug Dev Ind Pharm, 2007; 33(9):909-26.

Deb R, Ahmed AB. Pellets and pelletization techniques: a critical review. Int Res J Pharm, 2013; 4(4):90-5.

Doetsch W. Material handling and feeder technology. Drugs Pharm Sci, 2003; 133:111-34.

Dumpa NR, Sarabu S, Bandari S, Zhang F, Repka MA Chronotherapeutic drug delivery of ketoprofen and ibuprofen for improved treatment of early morning stiffness in arthritis using hot-melt extrusion technology. AAPS PharmSciTech, 2018; 19(6):2700-9.

Follonier N, Doelker E, Cole ET. Various ways of modulating the release of diltiazem hydrochloride from hot-melt extruded sustained release pellets prepared using polymeric materials. J Control Release, 1995; 36(3):243-50

Ghai D. Pelletization: an alternate to granulation. Pharma Times, 2011; 43(1):13-5

Ghebremeskel AN, Vemavarapu C, Lodaya M. Use of surfactants as plasticizers in preparing solid dispersions of poorly soluble API: selection of polymer-surfactant combinations using solubility parameters and testing the processability. Int J Pharm, 2007; 328(2):119-29.

Ghebre-Sellassie I, Knoch A. Pelletization techniques. In: Swarbick J, Boylan JC (eds.). Encyclopedia of pharmaceutical technology. Marcel Dekker Inc, New york, NY, vol. 3, 2002.

Griff AL. Plastics extrusion technology. Krieger Publishing Company, Malabar, FL, 1976.

Hengsawas Surasarang S, Keen JM, Huang S, Zhang F, McGinity JW, Williams III RO. Hot melt extrusion versus spray drying: hot melt extrusion degrades albendazole. Drug Dev Ind Pharm, 2017; 43(5):797-811.

Hinder RA, Kelly KA. Canine gastric emptying of solids and liquids. Am J Physiol Endocrinol Metab, 1977; 233(4):E335.

Hirjau M, Nicoara AC, Hirjau V, Lupuleasa D. Pelletization techniques used in pharmaceutical fields. Farma, 2011; 4(3):4.

Hitzer P, Bäuerle T, Drieschner T, Ostertag E, Paulsen K, van Lishaut H, Lorenz G, Rebner K. Process analytical techniques for hotmelt extrusion and their application to amorphous solid dispersions. Ana Bioanal Chem, 2017; 409(18):4321-33.

Jaiswar DR, Jha D, Amin PD. Preparation and characterizations of stable amorphous solid solution of azithromycin by hot melt extrusion. J Pharm Investig, 2016; 46(7):655-68.

Jankovic S, O’Dwyer PJ, Box KJ, Imanidis G, Reppas C, Kuentz M. Biphasic drug release testing coupled with diffusing wave spectroscopy for mechanistic understanding of solid dispersion performance. Eur J Pharm Sci, 2019; 137:105001.

Juslin LE. Measurement of droplet size distribution and spray angle from a pneumatic nozzle, and granule growth kinetics and properties of lactose, glucose and mannitol granules made in a fluidized bed granulator. Doctoral thesis, University of Helsinki, 1997.

Kandukuri JM, Allenki V, Eaga CM, Keshetty V, Jannu KK. Pelletization techniques for oral drug delivery. Int J Pharm Sci Drug Res, 2009; $1: 63-70$.

Keen JM, McGinity JW. Melt extruded controlled release dosage forms. In: Douroumis D (ed.). Melt extrusion. Springer, New york, NY, pp 243-60, 2013

Kristensen HG, Schaefer T. Granulation: a review on pharmaceutical wet-granulation. Drug Dev Ind Pharm, 1987; 13(4-5):80372

Kumari MH, Samatha K, Balaji A, Shankar MU. Recent novel advandcements in pellet formulation: a review. Int J Pharm Sci Res, 2013 4(10):3803.

Lachman L, Lieberman HA, Kanig JL. The theory and practice of industrial pharmacy. Lea \& Febiger, Philadelphia, 1986.

Lindén M. Hot-melt extrusion of modified release pelletsinfluence of the formulation and extrusion process on extended-and enteric 
release profile. Master of science thesis, Department of Chemical and Biological Engineering, Division of Pharmaceutical Technology, Chalmers University of Technology, Gothenburg, Sweden, 2012.

Luker K. Hot-melt extrusion: pharmaceutical applications. 1st edition, John Wiley Sons Ltd, Chichester, UK, pp 1-21, 2012.

Madan S, Madan S. Hot melt extrusion and its pharmaceutical applications. Asian J Pharm Sci, 2012;7(1):123-33.

Maniruzzaman M, Boateng JS, Snowden MJ, Douroumis D. A review of hot-melt extrusion: process technology to pharmaceutical products. ISRN Pharm, 2012; 2012:436763.

Maniruzzaman M, Rana MM, Boateng JS, Mitchell JC, Douroumis D. Dissolution enhancement of poorly water-soluble APIs processed by hot-melt extrusion using hydrophilic polymers. Drug Dev Ind Pharm, 2013; 39(2):218-27.

Manivannan R, Parthiban KG, Sandeep G, Balasubramaniam A, Senthilkumar N. Multiparticlate drug delivery systems: pellet \& pelletization technique. Drug Invent Today, 2010; 2(5):233-7.

Martin C. Continuous mixing of solid dosage forms via hot-melt extrusion. Pharm Technol, 2008; 32(10):76-86.

Martin C. Twin screw extrusion for pharmaceutical processes. In: Melt extrusion. Springer, New York, NY, pp 47-79, 2013.

McCrum NG, Buckley CP, Bucknall CB, Bucknall CB. Principles of polymer engineering. USA: Oxford University Press, New York, NY, 1997.

Organization WH. Stability testing of active pharmaceutical ingredients and finished pharmaceutical products. World Health Organ Tech Rep Ser, 2009; 953:87-123.

Patil H, Tiwari RV, Repka MA. Hot-melt extrusion: from theory to application in pharmaceutical Formulation. AAPS PharmSciTech, 2016; 17(1):20-42.

Politis SN, Rekkas DM. Pelletization processes for pharmaceutical applications: a patent review. Recent Pat Drug Deliv Formul, 2011; 5(1):61-78

Rahman MA, Ahuja A, Baboota S, Bali V, Saigal N, Ali J. Recent advances in pelletization technique for oral drug delivery: a review. Curr Drug Deliv, 2009; 6(1):122-9.

Rauwendaal C. Polymer extrusion. Carl Hanser Verlag $\mathrm{GmbH}$ Co KG, Munich, Germany, 2014.

Raval MK, Ramani RV, Sheth NR. Formulation and evaluation of sustained release enteric-coated pellets of budesonide for intestinal delivery. Int J Pharm Investig. 2013; 3(4):203.

Repka MA, Battu SK, Upadhye SB, Thumma S, Crowley MM, Zhang F, Martin C, McGinity JW. Pharmaceutical applications of hot-melt extrusion: part II. Drug Dev Ind Pharm, 2007; 33(10):1043-57.

Rowe RC, Sheskey P, Quinn M. Handbook of pharmaceutical excipients. Libros Digitales-Pharmaceutical Press, London, UK, 2009.

Schilling SU, McGinity JW. Novel application of hot-melt extrusion for the preparation of monolithic matrices containing entericcoated particles. Int J Pharm, 2010; 400(1-2):24-31.
Schilling SU, Shah NH, Malick AW, McGinity JW. Properties of melt extruded enteric matrix pellets. Eur J Pharm Biopharm, 2010; 74(2):352-61

Swathi P. Formulation and evaluation of rabeprazole sodium and domperidone pellets. Indo Am J Pharm Res, 2017; 7:235-41.

Thakkar R, Thakkar R, Pillai A, Ashour EA, Repka MA. Systematic screening of pharmaceutical polymers for hot melt extrusion processing: a comprehensive review. Int J Pharm, 2020; 576:118989.

Thiry J, Krier F, Evrard B. A review of pharmaceutical extrusion: critical process parameters and scaling-up. Int J Pharm, 2015; 479(1):22740

Vo AQ, Kutz G, He H, Narala S, Bandari S, Repka MA Continuous manufacturing of Ketoprofen delayed release pellets using melt extrusion technology: application of QbD design space, inline near infrared, and inline pellet size analysis. J Pharm Sci, 2020; 109(12):3598-607.

Vyas S, Jain A. Pelletization techniques: a review. Int J Pharm Life Sci, 2019; 10(3):31

Vyas SP, Khar RK. Controlled drug delivery concepts and advances. Vallabh Prakashan, 2002; 1:411-47.

Vynckier AK, De Beer M, Monteyne T, Voorspoels J, De Beer $\mathrm{T}$, Remon JP, Vervaet C. Enteric protection of naproxen in a fixed-dose combination product produced by hot-melt co-extrusion. Int J Pharm, 2015; 491(1):243-9.

Wilson M, Williams MA, Jones DS, Andrews GP. Hot-melt extrusion technology and pharmaceutical application. Ther Deliv, 2012; 3(6):787-97.

Yadav N, Verma A. Pharmaceutical pellets: a versatile carrier for oral controlled delivery of drugs. Indian J Pharm Educ, 2016; 50:S146-60.

Yang Y, Shen L, Li J, Shan W. Preparation and evaluation of metoprolol tartrate sustained-release pellets using hot melt extrusion combined with hot melt coating. Drug Dev Ind Pharm, 2017; 43(6):939-46.

Young CR, Crowley M, Dietzsch C, McGinity JW. Physicochemical properties of film-coated melt-extruded pellets. J Microencapsul, 2007; 24(1):57-71.

Young CR, Koleng JJ, McGinity JW. Properties of drugcontaining spherical pellets produced by a hot-melt extrusion and spheronization process. J Microencapsul, 2003; 20(5):613-25.

How to cite this article:

Roychowdhury R, Kara DD, Rathnanand M. Hot-melt extrusion technique: A novel continuous manufacturing method for enteric-coated pellets. J Appl Pharm Sci, 2021; 11(07):013-019. 